\title{
Note of Concern
}

\section{Editor's Note}

It has been brought to our attention that the Office of Research Integrity of the U.S. Department of Health and Human Services determined that Scott J. Brodie, DVM, Ph.D., formerly of University of Washington, "knowingly and intentionally falsified" 1 Figure $1 \mathrm{~N}$ and an inset within Figure $1 \mathrm{~K}$ in the article entitled "Pediatric AIDS-Associated Lymphocytic Interstitial Pneumonia and Pulmonary Arterio-Occlusive Disease: Role of VCAM-1/VLA-4 Adhe- sion Pathway and Human Herpesviruses," by Scott J. Brodie, Corazon de la Rosa, John Greg Howe, Jill Crouch, William D. Travis, and Kurt Diem (Volume 154, pages 1453-1464 of the May 1999 issue of The American Journal of Pathology).

\section{Reference}

1. Notices. Federal Register 2010, 75:24703-24704 